\title{
Long noncoding RNA HI9 is a critical oncogenic driver and contributes to epithelial-mesenchymal transition in papillary thyroid carcinoma
}

This article was published in the following Dove Medical Press journal: Cancer Management and Research

\author{
Wei-Quan Liang ${ }^{1, *}$ \\ De Zeng',* \\ Chun-Fa Chen' \\ Shu-Ming Sun' \\ Xiao-Feng Lu' \\ Chun-yan Peng ${ }^{3}$ \\ Hao-Yu Lin'
}

'Department of Thyroid and Breast Surgery, The First Affiliated Hospital of Shantou University Medical College, Shantou, Guangdong 5 I5000, People's Republic of China; ${ }^{2}$ Department of Medical Oncology, Cancer Hospital of Shantou University Medical College, Shantou 5 I503I, People's Republic of China; ${ }^{3}$ Department of Clinical Laboratory, Taihe Hospital of Hubei University of Medicine, Hubei 442008, People's Republic of China

*These authors contributed equally to this work
Correspondence: Hao-Yu Lin Department of Thyroid and Breast Surgery, The First Affiliated Hospital of Shantou University Medical College, Shantou, Guangdong 515000, People's Republic of China

Tel +8675488900232

Fax +8675488259850

Email rainlhy@stu.edu.cn
Background: Growing evidence has indicated that the long noncoding RNA H19 (IncRNA H19), frequently deregulated in almost all tumor types tested, acted as a pivotal contributor to both cancer initiation and progression. However, the role of $\operatorname{lncRNA} H 19$ in human papillary thyroid carcinoma (PTC) remains controversial. The aim of the study was to investigate the expression and potential function of $\operatorname{lncRNA} H 19$ in human PTC.

Patients and methods: The lncRNA H19 level was determined by quantitative real-time (RT)-PCR analyses in 58 PTC tissue samples and their paired paracancerous tissue samples. RNA interference, RT-PCR analysis, and Western blot assay were used to determine the impact of $\operatorname{lncRNA} H 19$ on epithelial-mesenchymal transition (EMT) markers in human PTC cells. The migratory and invasive capacities of PTC cells were determined by wound-healing and transwell migration and invasion assays.

Results: IncRNA H19 expression was 2.417-fold higher in PTC tissues than their paired paracancerous tissue (95\% CI: 1.898-2.935, P<0.0001). Higher level of $\operatorname{lncRNAH19}$ was correlated to elevated expression of Vimentin, ZEB2, Twist, and Snail2. Inhibition of lncRNA H19 resulted in upregulation of $E$-cadherin and downregulation of Vimentin both at mRNA and protein levels. Conversely, enforced expression of the exogenous IncRNA H19 led to E-cadherin mRNA and protein downregulation and relative upregulation of Vimentin. Moreover, wound-healing and transwell migration and invasion assays showed that $\operatorname{lncRNAH19}$ could promote the migratory and invasive abilities of PTC cells.

Conclusion: The level of $\operatorname{lncRNA} H 19$ was significantly higher in PTC tissues than paired paracancerous tissue or normal tissues. Overexpression of $\operatorname{lncRNAH19}$ was correlated with higher tumor burden of PTC. It also contributes to EMT process, as well as promotes migration and invasion of PTC cells.

Keywords: long noncoding RNA H19 (IncRNA H19), papillary thyroid carcinoma, epithelialmesenchymal transition

\section{Introduction}

Growing concern over the sharp increase in the prevalence of thyroid cancer in past decades, particularly papillary thyroid carcinoma (PTC), has prompted investigators to explore the molecular underpinnings of the disease, leading to the identification of BRAFV600E and RAS mutations, as valid therapeutic targets. ${ }^{1-3}$ Recently, the Encyclopedia of DNA Elements project, which was designed to discover and characterize novel RNAs transcripts, has revealed that a large amount of primary or processed protein-coding and noncoding transcripts, including thousands of long noncoding 
RNAs (IncRNAs), are predominantly implicated in the human genome. ${ }^{4,5}$ Notably, increasing studies have demonstrated that deregulated expression of lncRNAs was significantly involved in the pathogenesis of multiple types of cancer. ${ }^{6,7}$

The lncRNAs are a new class of nonprotein transcripts with over 200 bases in length. ${ }^{8}$ Emerging evidence has indicated that the $\operatorname{lncRNAH19}$, frequently deregulated in almost all tumor types tested, acted as a critical contributor to both cancer initiation and progression. ${ }^{9} \mathrm{Li}$ et al reported that overexpression of $\ln c \mathrm{RNA} H 19$ enhances carcinogenesis and metastasis of gastric cancer. ${ }^{10}$ Guan et al reported that overexpression of $\ln c R N A$ H19/miR-675 promotes tumorigenesis in head and neck squamous cell carcinoma. ${ }^{11}$ A study by Shi et al demonstrated that $\operatorname{lncRNAH19}$ predicts poor prognosis in patients with melanoma and regulates cell growth, invasion, migration, and epithelial-mesenchymal transition (EMT) in melanoma cells. ${ }^{12}$ Moreover, preclinical and clinical studies have highlighted the therapeutic potential against $\ln c R N A$ $H 19$. For instance, Zhao et al showed that downregulation of lncRNA H19 inhibits migration and invasion of human osteosarcoma through the NF- $\kappa \mathrm{B}$ pathway. ${ }^{13}$

Despite enormous breakthroughs in the understanding of the role of $\ln c R N A$ H19 in multiple types of tumor progression, the exact role and function of $\operatorname{lncRNAH} H 9$ in human PTC remain under-investigated. A major mechanism through which BRAF mutation might contribute to primary PTC progression is through induction of EMT. ${ }^{14,15}$ Specifically, the Snail/E-cadherin axis has been demonstrated as a pathway dysregulated by BRAF, leading to EMT. ${ }^{16}$ The possibility that IncRNA H19 can regulate EMT program is an attractive option to explore. In this study, we identified that the $\ln C R N A$ $H 19$ was significantly increased in PTC tissues and associated with classic EMT markers in PTCs, suggesting that lncRNA H19 may be required for human PTC tumorigenesis and development.

\section{Patients and methods}

\section{Patients and clinical tissue samples}

Written informed consents were received from all patients before enrollment, and this study was approved by the Ethics Committee of Shantou University Medical Hospital. Fifty-eight PTC tissue samples and their paired paracancerous tissue samples were obtained from patients (age range: 27-72 years; 16 males and 42 females), who were first diagnosed between June 2016 to December 2017 at the First Affiliated Hospital of Shantou University Medical Hospital for quantitative real-time (qRT)-PCR analyses and paraffin-embedded pathological investigation. All medical histories of the patients were well-documented according to the eighth edition of the American Joint Committee on Cancer TNM system. ${ }^{17}$

\section{Cell lines and cell culture}

The human PTC cell line B-CPAP was purchased from the Chinese Academy of Sciences (Beijing, China). This cell line was established from the tumor tissue of a woman aged 72 years with metastatic PTC in $1992 .{ }^{18}$ Cells were cultured in RPMI-1640 medium, containing 10\% FBS, $100 \mathrm{U} / \mathrm{mL}$ penicillin, and $100 \mathrm{mg} / \mathrm{mL}$ streptomycin (all from Thermo Fisher Scientific, Waltham, MA, USA) in a $5 \% \mathrm{CO}_{2}$ incubator at $37^{\circ} \mathrm{C}$.

\section{RNA purification and RT-PCR analysis}

All obtained tissues during surgery were immediately stored in liquid nitrogen prior to use. Total RNA $(1 \mu \mathrm{g})$ was isolated from tissues or cells using TRIzol (Thermo Fisher Scientific) following the manufacturer's instructions and stored at $-80^{\circ} \mathrm{C}$. Reverse transcription was performed using a PrimeScript $^{\text {TM }}$ RT reagent kit (Takara Bio Inc., Shiga Prefecture, Japan) according to the manufacturer's instructions. To detect mRNA expression, qRT-PCR was performed with an SYBR Select Master Mix (Thermo Fisher Scientific) and a CFX96 RT-PCR Detection System (Bio-Rad Laboratories Inc., Hercules, CA, USA). To normalize the amount of mRNA in each sample, GAPDH was used. Primer sequences used in RT-PCR are listed in Table S1.

\section{Small interfering RNAs (siRNAs) and transfection}

The siRNAs were purchased from Suzhou GenePharma Co., Ltd. (Suzhou, China). The siRNAs are shown in Table S2. Cells were transfected using Lipofectamine 3000 (Life Technologies, Carlsbad, CA, USA). A total of $1 \times 10^{6}$ B-CPAP cells were inoculated into each well of a 6-well culture plate. The next day, 75 pmol of siRNA was combined with 3.75 $\mu \mathrm{L}$ of Lipofectamine 3000 (Life Technologies) by strictly following the manufacturer's instructions.

\section{Western blot assay}

Cells were lysed in RIPA buffer (Cell Signaling Technology, Danvers, MA, USA) with protease inhibitors. The extracted protein sample was measured using the BCA protein assay and was stored at $-80^{\circ} \mathrm{C}$ until required for use. The $30 \mu \mathrm{g}$ protein sample was separated by $8 \%$ SDS-PAGE and transferred onto a PVDF membrane (EMD Millipore, Billerica, MA, USA). After transferring, the membrane was blocked in 
$5 \%$ nonfat milk and then incubated with primary antibodies at $4{ }^{\circ} \mathrm{C}$ overnight. The antibodies are shown in Table S3. The next day, the membrane was incubated with secondary antibodies and subjected to electrochemiluminescence detection (Applygen Technologies, Inc., Beijing, China).

\section{Wound healing assay}

Thirty minutes before the application of injury lines, B-CPAP cells were treated with Mitomycin C (25 mg/mL) (Beyotime Institute of Biotechnology, Jiangsu, China). Injury line was made with a 2-mm wide tip separated on cells plated in culture dishes at $90 \%$ confluency. After washing with PBS, cells could migrate in complete medium and photographs were taken $(\times 40)$ after 48 hours. An average of five random widths of each injury line was measured for quantitation.

\section{Transwell invasion assays}

Cell culture inserts ( $8 \mathrm{M}$ pore size; BD, Franklin Lakes, NJ, USA) and Matrigel invasion chambers (BD) were used to perform migration and invasion assays, respectively. Transfected cells were serum-starved for 24 hours and then $3 \times 10^{4}$ B-CPAP cells in serum-free medium were seeded into the upper chamber. Complete medium was added to the bottom chamber. Cells were stained with $0.1 \%$ crystal violet for migration assays after 36 and 48 hours for invasion assays. Each assay was performed in triplicate. The number of cells from five fields in each well were counted by two investigators (HYL and DZ).

\section{Clinical databases}

The ONCOMINE datasets (http://www.oncomine.org/) were used to analyze the expression of $\operatorname{lncRNAH} H 19$ in various cancers against normal tissue as well as the correlated expression genes in thyroid cancer. ${ }^{19}$ The correlations between the expression levels of $\operatorname{lncRNAH19}$ and Vimentin, ZEB2, Twist, or Snail2 in thyroid cancers were determined through analysis in the cBioPortal database (http://www.cbioportal.org/index. do). ${ }^{20}$ We analyzed thyroid carcinoma (TCGA, Provisional) and PTC (TCGA, Cell 2014) datasets. The expression levels of $\operatorname{lncRNAH19}$ in a series of cancers were analyzed by CCLE database (https://portals.broadinstitute.org/ccle/ home), which is an online encyclopedia of a compilation of gene expression, chromosomal copy number, and massively parallel sequencing data from 947 human cancer cell lines. ${ }^{21}$

\section{Statistical analysis}

Statistical analysis was performed using the SPSS version 18.0. Data from three independent experiments were presented as the mean $\pm \mathrm{SD}$. Statistical analysis was performed using Mann-Whitney U test and Wilcoxon signed-rank test. The clinicopathological characteristics were analyzed using Pearson's chi-squared test. Difference between multiple groups was analyzed by two-way ANOVA. For clinical data from ONCOMINE and cBioPortal datasets, Student's t-test was used, and two times of fold change with a $P$-value of $<0.01$ was defined as clinically significant, Correlation coefficients between RNA levels were obtained through Spearman's rank correlation analysis as was described earlier. ${ }^{22} \mathrm{~A}$ value of $P<0.05$ was considered as a statistically significant.

\section{Ethical statement}

The study was approved by the ethics committee of the First Hospital of Shantou University Medical College. Patient consent was written informed consent, in compliance with the Declaration of Helsinki.

\section{Results}

The expression level of IncRNA HI9 was significantly increased in PTC tissues

$\operatorname{lncRNAH} H 19$ has been identified as an oncogenic gene in multiple cancer types and its elevated expression was tightly linked to tumorigenesis and cancer progression. ONCOMINE analysis revealed that $\operatorname{lncRNA} H 19$ expression was significantly higher in cancer than normal samples across a wide variety of datasets in different cancer types. A total of 220 different types of studies about $\operatorname{lncRNA} H 19$ were collected in the ONCOMINE database (Figure S1) in which 37 studies showed the increase of $\ln C R N A H 19$ expression and 22 studies showed a decrease. In addition, CCLE analysis demonstrated that the expression level of $\operatorname{lncRNAH} H 19$ in thyroid cancer cells ranked the eleventh highest in a variety of cancer cell lines tested (Figure S2). Thus, we performed the qRT-PCR assay to detected PTC tissue samples and corresponding adjacent nontumorous tissues samples from 58 patients who were first diagnosed in our hospital. Our data showed that lncRNA H19 expression was 2.417-fold higher (95\% CI: 1.898-2.935) in PTC tissues than their paired paracancerous tissues (Figure $1 \mathrm{~A}, P<0.0001$ ). These results implied that $\operatorname{lncRNAH19}$ may be distinctively expressed higher in thyroid cancer, suggesting it might play unique roles in the development of thyroid cancer.

\section{Elevated IncRNA HI 9 expression correlated with tumor burden of PTC}

To further investigate the correlation between lncRNA H19 expression and clinicopathological features, qRT-PCR analy- 
A

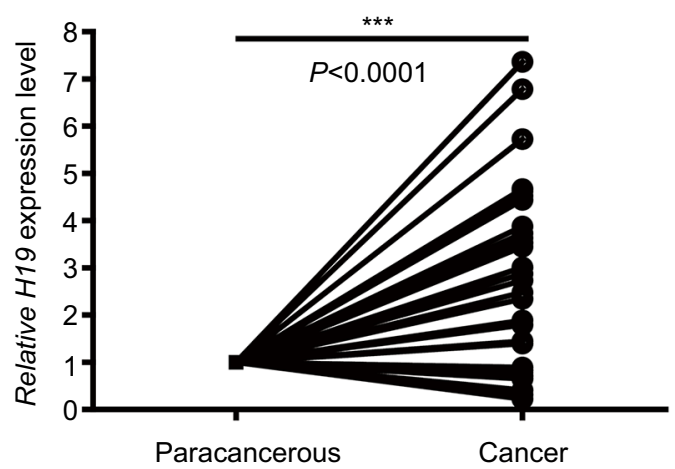

C

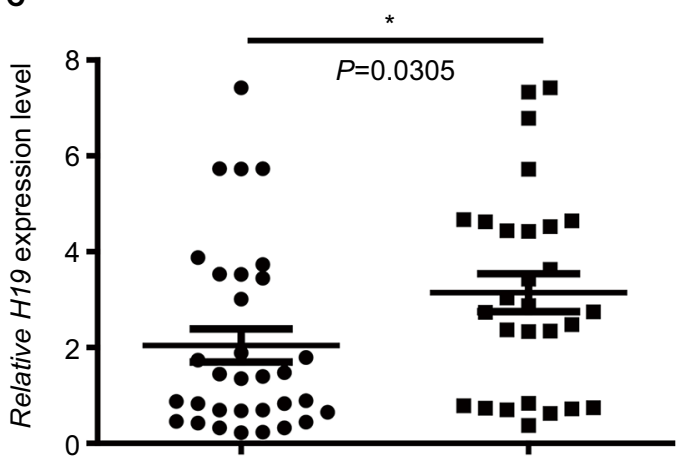

Non-metastasis

LN-metastasis
B

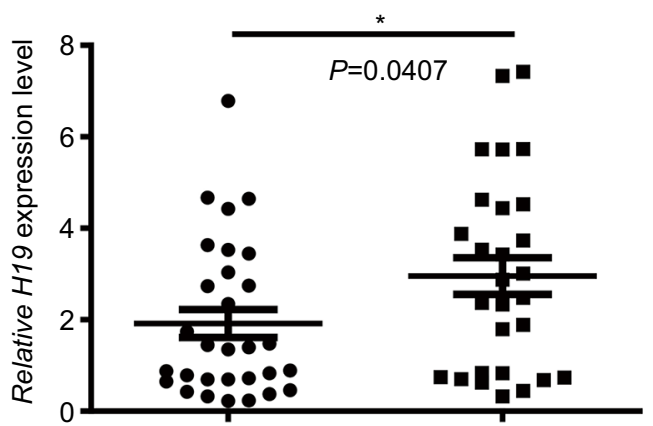

$\mathrm{T}<1.5 \mathrm{~cm}$

$\mathrm{T} \geq 1.5 \mathrm{~cm}$

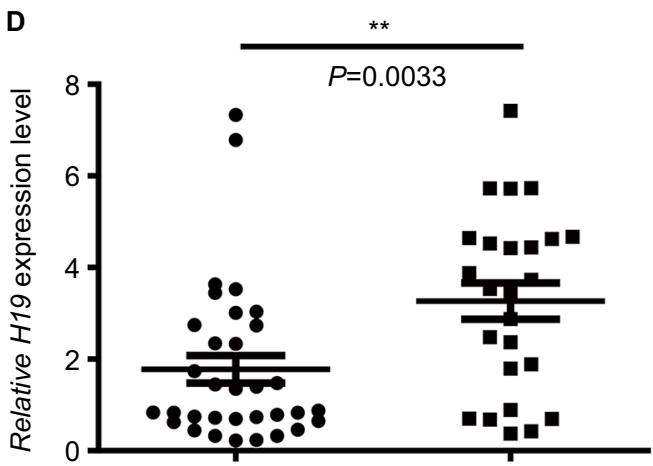

Stage I+II

Stage III+IV

Figure I Analysis of IncRNA HI9 expression in PTC patients according to qRT-PCR.

Notes: (A) Relative expression of $H / 9$ in cancer group and paracancerous group. (B) Relative expression of $H / 9$ in $\mathrm{T}<\mathrm{I.5} \mathrm{cm}$ group and $\mathrm{T} \geq \mathrm{I} .5 \mathrm{~cm}$ group. (C) Relative expression of $\mathrm{HI} 9$ in non-metastasis group and lymph node metastasis group. (D) Relative expression of $H I 9$ in stage $\mathrm{I}+\mathrm{II}$ group and stage III+IV group ( $* P<0.05$, $* * P<0.0 \mathrm{I}$, and $* * * P<0.001)$.

Abbreviations: IncRNA HI9, long noncoding RNA HI9; PTC, papillary thyroid carcinoma; qRT-PCR, quantitative real-time PCR.

ses of lncRNA $H 19$ were performed using samples from 58 PTC patients. When the 58 tumor tissues were stratified on clinical progression, we found that higher lncRNA H19 expression is remarkably associated with increased tumor size (Figure 1B, $P=0.0407$ ). In addition, IncRNA H19 expression levels were much higher in lymph node metastasis group than those in patients without lymph node metastasis (Figure $1 \mathrm{C}, P=0.0305)$. Moreover, high IncRNA H19 expression was correlated with PTC patients of stage III/IV than those in patients with stage I/II (Figure 1D, $P=0.0033$ ). Consistently, when 58 PTC patients were divided into two group, $\operatorname{lnc} R N A$ $H 19^{\text {High }}$ (>median), and lncRNA H19 ${ }^{\text {Low }}$ (<median), our data also revealed that more patients in increased tumor size group ( $P=0.036)$, lymph node metastasis group $(P=0.002)$, and higher stage group $(P=0.004)$ correlated with $\ln c R N A$ $H 19^{\text {High }}$ group (Table 1). However, the level of IncRNA H19 expression was not associated with age, gender, extrathyroidal extension status, pathological subtype, and whether combined with nodular goiter between these two groups (Table 1). It was, therefore, postulated that the high $\operatorname{lncRNA} H 19$ expression level was correlated with more malignant phenotypes with increased proliferation and potential of metastasis in PTC.

\section{Higher expression of IncRNA HI9 correlated with elevated expression of mesenchymal phenotypes markers} Vimentin, ZEB2, Twist, and Snail2

To explore the inherent properties of IncRNA H19 and its potential mechanism in PTC, we used the ONCOMINE and cBioPortal databases to analyze the correlation of $\ln c R N A$ H19 in connection with other featured biomarkers in PTC. Interestingly, in ONCOMINE co-expression analysis, it was found that lncRNA H19 expression was significantly correlated with the expression of $Z E B 2$, a typical mesenchymal phenotypes marker (Figure 2, r=0.700). Moreover, gene correlation targeted analysis from TCGA database showed that in thyroid carcinoma, higher expression of $\operatorname{lncRNA}$ 
Table I Clinicopathological characteristics of 58 PTC patients according to $\mathrm{H} / 9$ expression

\begin{tabular}{|c|c|c|c|}
\hline $\begin{array}{l}\text { Clinicopathological } \\
\text { features }\end{array}$ & $\begin{array}{l}\mathrm{H} / 9^{\text {High }} \\
(>\text { median, } \\
\mathrm{n}=29)\end{array}$ & $\begin{array}{l}\text { HI9 Low } \\
\text { (<median, } \\
\mathrm{n}=29)\end{array}$ & $P$-value \\
\hline Age & & & 0.115 \\
\hline$<55$ years & 17 & II & \\
\hline$\geq 55$ years & 12 & 18 & \\
\hline Gender & & & 0.240 \\
\hline Male & 6 & 10 & \\
\hline Female & 23 & 19 & \\
\hline Tumor size & & & $0.036^{\mathrm{a}}$ \\
\hline$\leq 2 \mathrm{~cm}$ & II & 19 & \\
\hline$>2 \mathrm{~cm}$ & 18 & 10 & \\
\hline LN metastasis & & & $0.002^{\mathrm{a}}$ \\
\hline Yes & 20 & 8 & \\
\hline No & 9 & 21 & \\
\hline Distance metastasis & & & 1.000 \\
\hline Yes & 27 & 27 & \\
\hline No & 2 & 2 & \\
\hline Clinical stage & & & $0.004^{\mathrm{a}}$ \\
\hline $\mathrm{I}+\mathrm{II}$ & II & 22 & \\
\hline III+IV & 18 & 7 & \\
\hline Extrathyroidal extension & & & 0.581 \\
\hline Yes & 18 & 20 & \\
\hline No & II & 9 & \\
\hline Pathological subtype & & & 0.730 \\
\hline Classical & 25 & 23 & \\
\hline Follicular & 4 & 6 & \\
\hline \multicolumn{4}{|l|}{ Nodular goiter } \\
\hline Yes & 12 & II & 0.788 \\
\hline No & 17 & 18 & \\
\hline
\end{tabular}

Notes: a $P$-value $<0.05$ was considered statistically significant.

Abbreviations: LN, lymph node; PTC, human papillary thyroid carcinoma.

$H 19$ correlated with elevated mesenchymal biomarker Vimentin (Figure 3A, $\mathrm{r}=0.22, P<0.001$ ), ZEB2 (Figure 3C, $\mathrm{r}=0.19, P<0.001$ ), Twist (Figure 3E, $\mathrm{r}=0.56, P<0.001$ ), and Snail2 (Figure 3G, r=0.48, $P<0.001$ ). Meanwhile, correlation analysis in PTC showed that elevated $\operatorname{lncRNA} H 19$ correlated with increased expression of Vimentin (Figure 3B, $\mathrm{r}=0.20, P<0.001$ ), ZEB2 (Figure 3D, $\mathrm{r}=0.23, P<0.001$ ), Twist (Figure 3F, $\mathrm{r}=0.57, P<0.001$ ), and Snail2 (Figure $3 \mathrm{H}$, $\mathrm{r}=0.50, P<0.001)$. These results showed that the expression of lncRNA H19 in PTC positively associated with mesenchymal phenotypes marker, which imply that $\operatorname{lncRNAH} H 19$ might play a distinct role in the processing of EMT and lead to more aggressive clinicopathological features of PTC.

\section{IncRNA HI 9 regulates mRNA and protein expression of EMT markers E-Cadherin and Vimentin}

Since the above data from the public database and clinical sample have shown that $H 19$ was correlated with EMT in PTC, we verified whether $\ln c R N A H 19$ was associated with typical EMT markers in PTC cell line B-CPAP. Suppression of $\ln c R N A$ $H 19$ by siRNA caused a significant upregulation of epithelial marker E-cadherin expression at both the mRNA and protein levels, while that of Vimentin, a mesenchymal marker, decreased as compared to controls (Figure 4A and B). Two different siRNA sequences were used to silence $\operatorname{lncRNAH} 19$ separately to exclude the possibility of nonspecific target. It was found that siH19-a and siH19-b effectively suppressed lncRNA H19 and finally caused downregulated Vimentin, while upregulating E-cadherin both at mRNA and protein levels (Figure 4A and B). We chose siH19-b with better suppression effect on $\operatorname{lncRNA}$ $H 19$ for further experiments. Conversely, enforced expression of the exogenous lncRNA H19 led to E-cadherin $m R N A$ and protein downregulation and relative upregulation of Vimentin (Figure 4C and D). These results implied that $\operatorname{lncRNAH}$ H9 was able to mediate the process of EMT in PTC cells.

\section{InCRNA HI 9 promotes migration and invasion abilities of PTC cells}

To evaluate whether the expression of $\ln c R N A$ H19 regulates cellular function via inducing EMT, we performed gain-offunction and loss-of-function studies on B-CPAP cells. We first assessed the effect of $\operatorname{lncRNA} H 19$ knockdown on cell motility via a wound healing assay. As displayed in Figure 5A, after culturing for 48 hours, the width of the scratch wound in siH19-b B-CPAP cells had reduced to $75 \%$ as compared to 0 hours, while the width of the scratch wound in control cells had reduced to $46 \%$ as compared to 0 hours (Figure 5B), indicating that loss of $\operatorname{lncRNAH} 19$ expression inhibits cell motility. In contrast, when enforcing expression of the exogenous lncRNA H19 in B-CPAP cells, the scratch wound width had healed to $26 \%$ as compared to 0 hours, dwarfing the $44 \%$ gap healed by control cells. This result suggests that $\operatorname{lncRNAH} H 19$ overexpression was capable of promoting the motility of B-CPAP cells (Figure 5C). We further investigated whether IncRNA H19 influenced the migration and invasion abilities of B-CPAP cells via transwell migration and invasion assays. As shown in Figure 5D, the number of migrated cells transfected with siH19 was significantly lower $(\sim 52 \%)$ than the number of migrated cells transfected with si-control (Figure 5F). Similarly, invasion assays showed that knocking down $\operatorname{lnc} R N A H 19$ via siRNAs resulted in fewer cells invading through the Matrigel-coated membrane (Figure $5 \mathrm{E}$ and $\mathrm{G})$. Moreover, the ectopic expression of $\operatorname{lncRNAH} \mathrm{H} 9$ in B-CPAP cells promoted cellular migration and invasion (Figure 5D-G). These results indicate that IncRNA H19 enhances the migration and invasion abilities of PTC cells. 

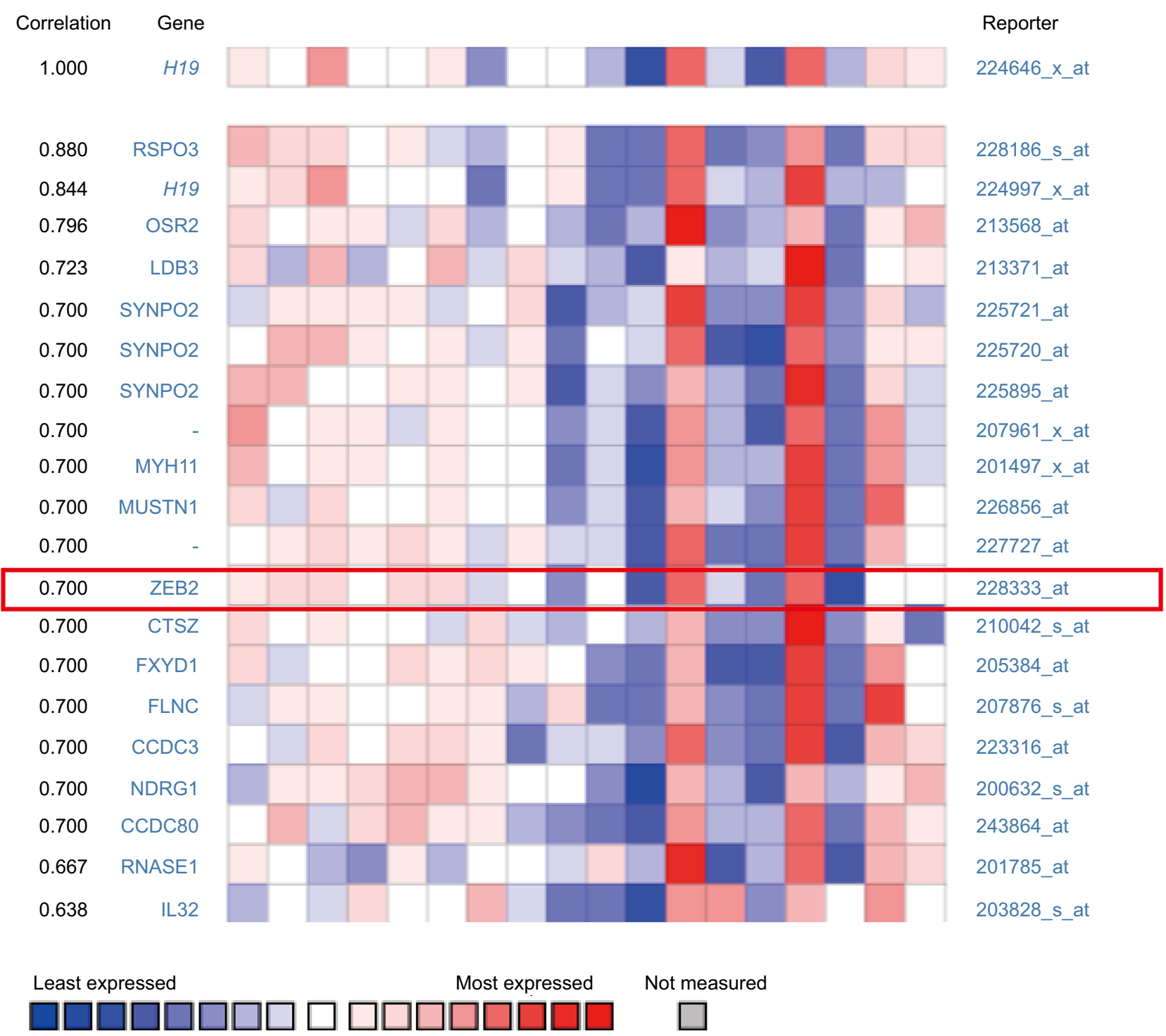

Figure 2 HI9 expression was significantly correlated with ZEB2 expression in thyroid carcinoma (shown in red frame, from ONCOMINE correlation analysis).

\section{Discussion}

Thyroid cancer is the most common endocrine malignancy across the world. ${ }^{1}$ Its prevalence has been steadily increasing in the past few decades, primarily due to a remarkable increase in the incidence of PTC. ${ }^{23}$ Multiple patterns of genetic alteration, including BRAF mutations, RAS mutations, and RET/PTC rearrangements, have been identified to be critically involved in the tumorigenesis and progression of PTCs. ${ }^{24}-26$ Targeting therapies toward these genetic alterations have led to a significant improvement in the therapeutic response and survival of patients with PTCs. ${ }^{27}$ Except for a series of protein-coding genetic alteration, a variety of noncoding transcripts have also been found to play essential roles in the development of a number of solid tumors. ${ }^{28-30}$ However, up to now, the alteration in the noncoding transcript in PTCs remained under-investigated. It has been recognized in most studies that IncRNA H19 overexpresses and contributes to tumorigenesis and progression of multiple cancer types, including gastric cancer, glioma, and head and neck squamous cell carcinoma. ${ }^{10,11,31}$ Nevertheless, it was found that $\operatorname{lncRNA} H 19$ was under-expressed in intratumoral hepatocellular carcinoma (HCC) tissues, as compared to peritumoral tissues. Moreover, IncRNA H19 could suppress the progression and metastasis of $\mathrm{HCC} .{ }^{32} \mathrm{Lv}$ et al also reported that downregulation of $\operatorname{lncRNAH} \mathrm{H} 9$ and MiR-675 promotes migration and invasion of human HCC cells through AKT/ GSK-3beta/Cdc25A signaling pathway. ${ }^{33}$ 
A

Thyroid carcinoma (TCGA, provisional)

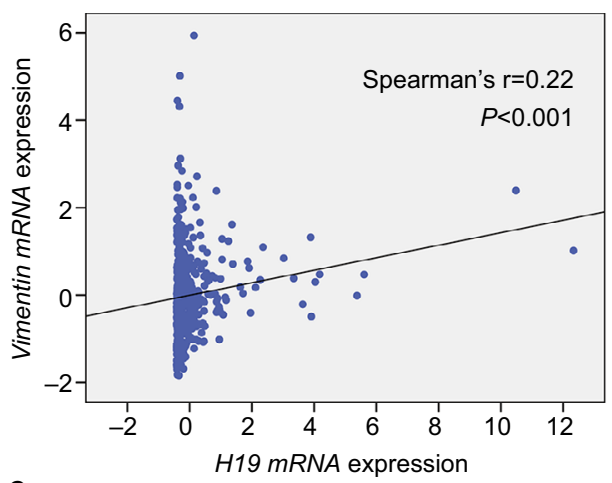

C

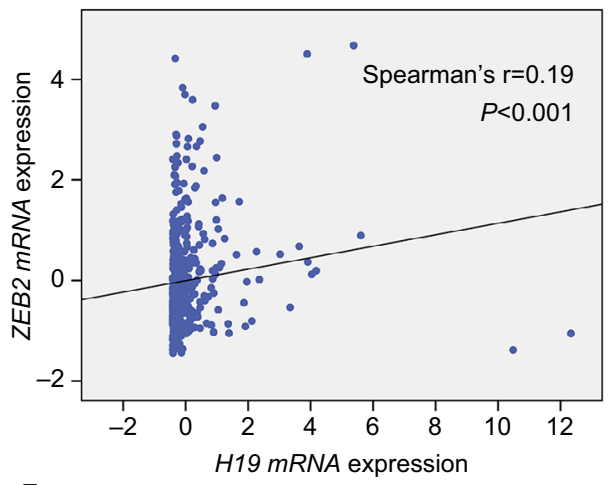

E

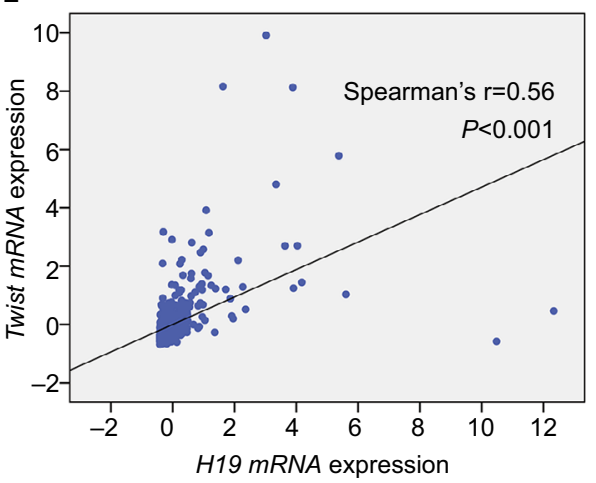

G

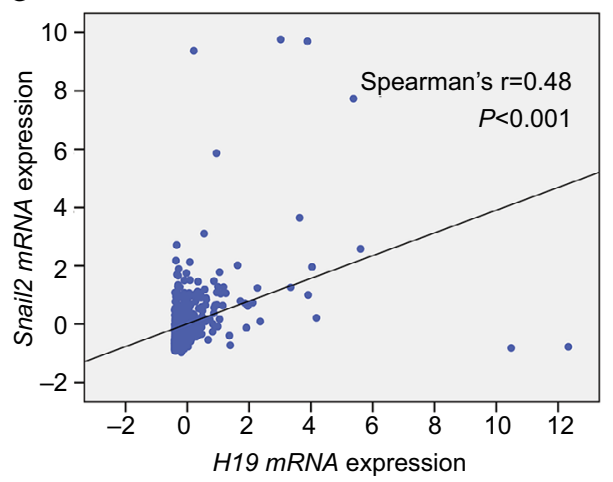

B Papillary thyroid carcinoma (TCGA, cell 2014)

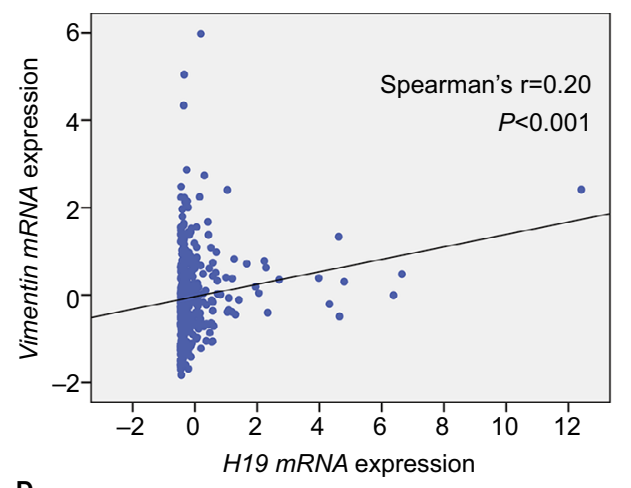

D

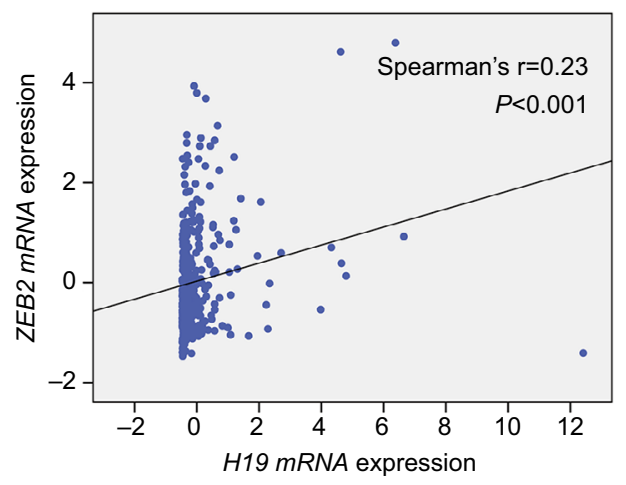

F

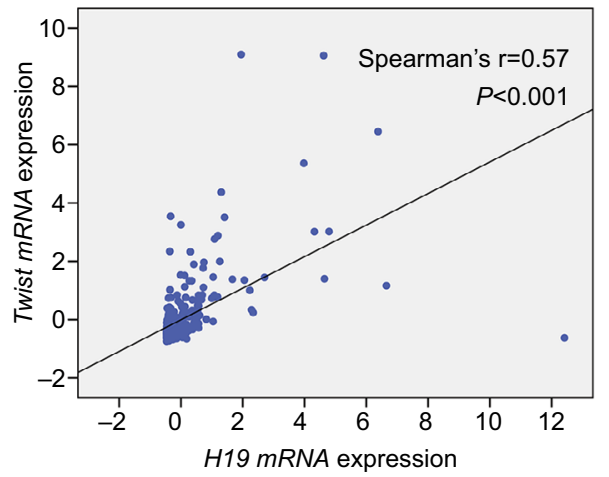

H

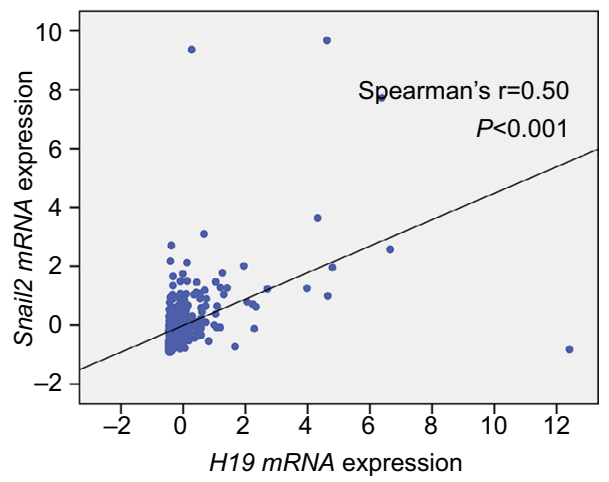

Figure 3 Elevated HI9 expression correlated with higher expression of Vimentin, ZEB2, Twist, and Snail2 in thyroid carcinoma.

Notes: In the TCGA (the Cancer Genome Atlas) database, the Pearson's chi-squared test was performed to analyze the correlation of $H$ I 9 and some typical mesenchymal markers. (A and B) Gene correlation targeted analysis between HI9 and Vimentin in samples of (A) thyroid carcinoma or (B) PTC. (C and D) Gene correlation targeted analysis between HI9 and ZEB2 in samples of (C) thyroid carcinoma or (D) PTC. (E and F) Gene correlation targeted analysis between HI9 and Twist in samples of (E) thyroid carcinoma or (F) PTC. (G and $\mathbf{H})$ Gene correlation targeted analysis between HI9 and Snail2 in samples of $(\mathbf{G})$ thyroid carcinoma or $(\mathbf{H})$ PTC.

Abbreviation: PTC, human papillary thyroid carcinoma. 
A

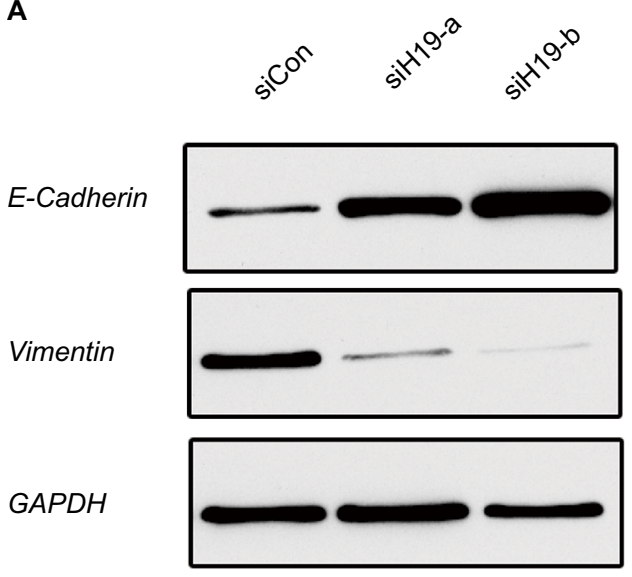

C

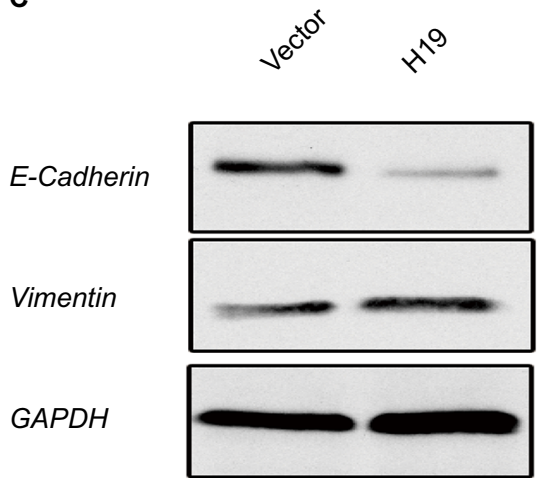

B

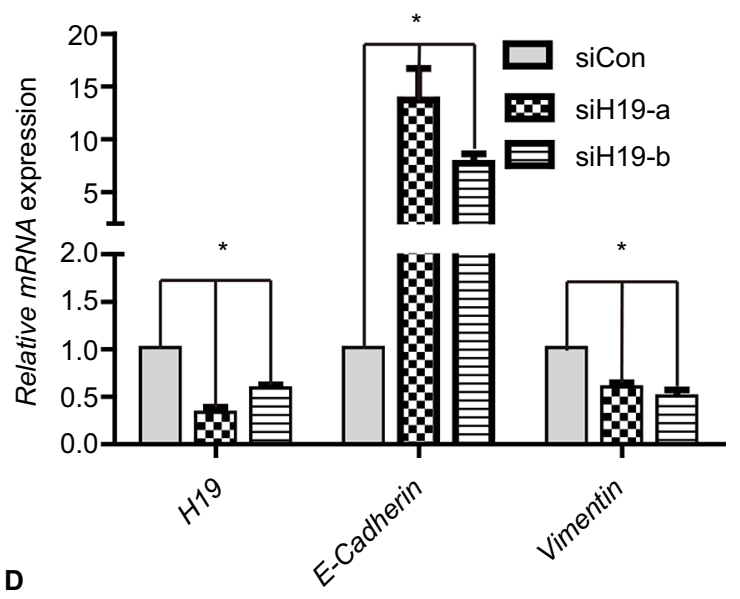

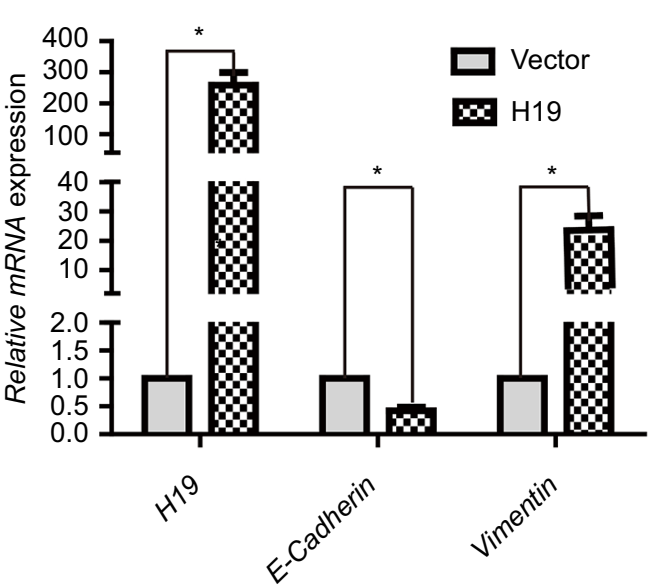

Figure 4 HI 9 regulates expression of EMT marker E-cadherin and Vimentin in PTC cells.

Notes: (A and B) Expression of E-cadherin and Vimentin in B-CPAP cells at protein and mRNA levels analyzed by (A) Western blot and (B) RT-PCR, respectively, when silencing HI9 by siHI9-a and siHI9-b. (C and D) Expression of E-cadherin and Vimentin in B-CPAP cells at protein and mRNA levels analyzed by (C) Western blot and (D) RT-PCR, respectively, when overexpressing HI9. *P<0.05 as compared to control groups.

Abbreviations: EMT, epithelial-mesenchymal transition; PTC, papillary thyroid carcinoma; RT-PCR, real-time PCR.

IncRNA H19 has been recognized to act as an oncogenic driver in a number of cancer types, such as gastric, breast, and lung cancers. ${ }^{34-36}$ However, the specific function of $\operatorname{lncRNA} \mathrm{H19}$ in thyroid cancer remains controversial. For example, Wang et al reported that $\operatorname{lncRNA} H 19$ represses cell viability, and restrains migratory and invasive capabilities of thyroid cancer cells through downregulation of IRS- $1{ }^{37}$ Lan et al demonstrated that inhibition of $\operatorname{lnc} R N A$ $H 19$ promotes the proliferation and motility of PTC. ${ }^{38} \mathrm{On}$ the contrary, Liu et al reported that increased lncRNA H19 expression levels are associated with poor prognosis in thyroid cancer patients. ${ }^{39}$ Another study by Liu et al suggested that increased expression of IncRNA H19 promoted growth, migration, and invasion in thyroid cancer, whereas $H 19$ knockdown impaired TC cell viability. ${ }^{40}$ Our analysis in the ONCOMINE database demonstrated that $\ln c R N A$ H19 expression was markedly higher in thyroid cancer than normal tissue samples. Particularly, the qRT-PCR assay of 58 PTCs and corresponding adjacent nontumorous tissues from our institution also showed that lncRNA H19 expression was considerably higher in PTC tissues than paired paracancerous tissues. These findings consistently suggested that $\operatorname{lncRNA}$ $H 19$ distinctively was expressed higher in PTCs than normal counterparts. Notably, we found that higher IncRNA H19 level was remarkably associated with larger tumor size, increased number of lymph node metastasis, as well as more advanced clinical stage, implying that higher IncRNA H19 level is correlated to higher tumor burden of PTCs.

Notably, emerging evidences in recent years indicated that $\operatorname{lncRNAH} H 19$ acts as an important inducer of EMT. ${ }^{12,36,41}$ 
A

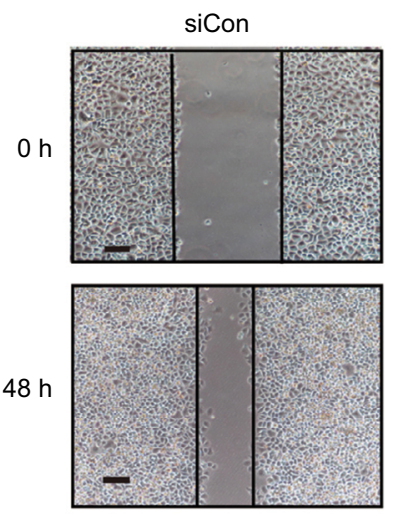

B

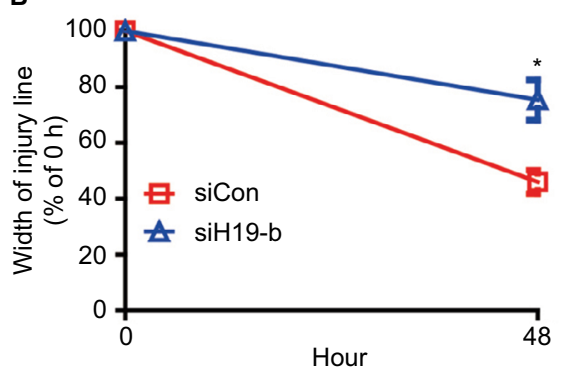

D

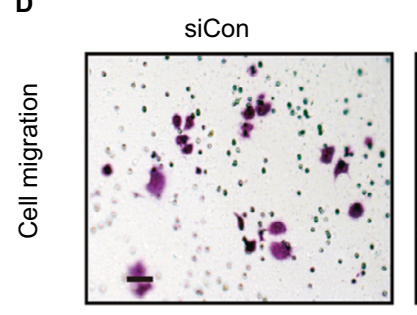

E
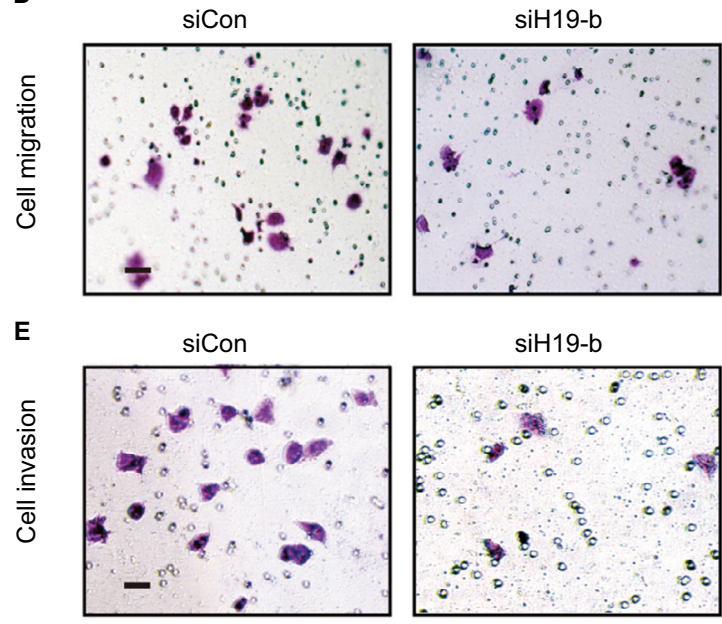

siH19-b

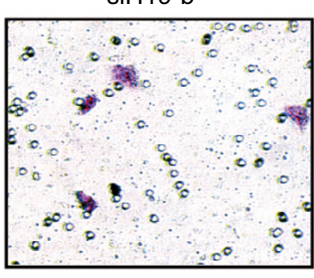

$\mathbf{F}$

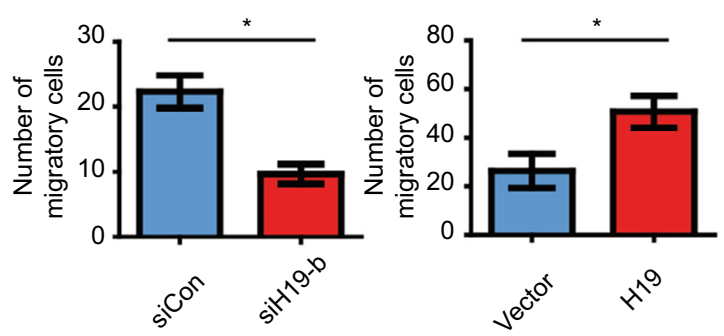

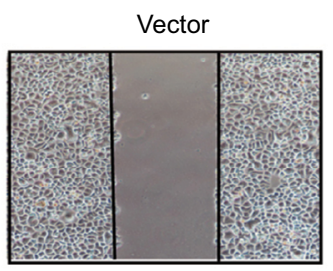
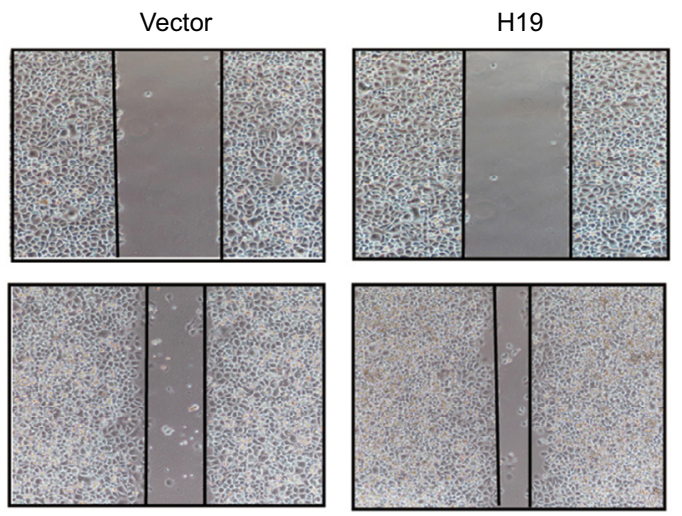

C
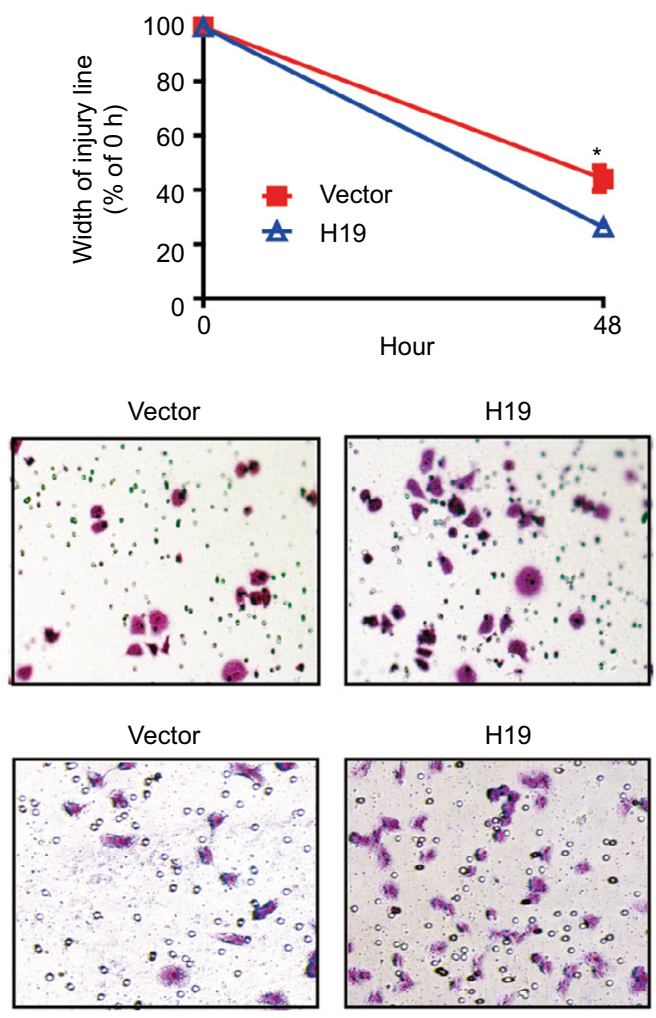

G

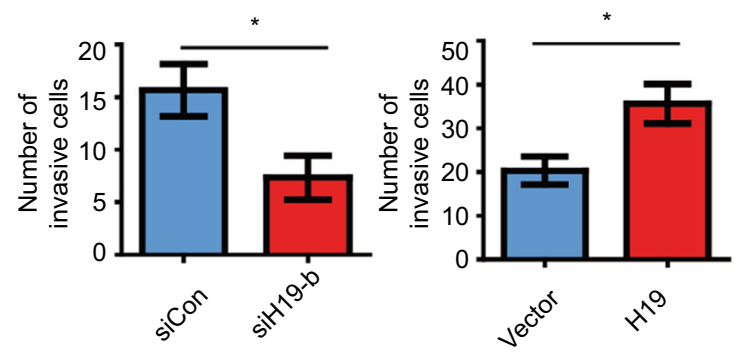

Figure 5 HI9 knockdown in B-CPAP cells inhibits EMT while overexpression promotes EMT.

Notes: (A-C) Wound healing assay showed the knockdown of $H / 9$ inhibited the cellular motility of B-CPAP cells, while overexpression of $H / 9$ enhanced such motility. (A) Representative pictures and (B and $\mathbf{C}$ ) quantitative data of wound recovery after 48 hours cell culture. Each sample contained three wells. (D-G) Knockdown of $H / 9$ decreased the cellular migration and invasion of B-CPAP cells; while overexpression of HI 9 enhanced such motility. (D) Representative pictures of migration and (E) invasion, (F) quantitative data of migration, or (G) invasion assays. All experiments were performed at least thrice and data were statistically analyzed by two-way ANOVA. $* P<0.05$ vs control. Error bars indicate SD.

Abbreviation: EMT, epithelial-mesenchymal transition. 
Matouk et al have reported that the role of the oncofetal lncRNA H19 in tumor metastasis orchestrating the EMTMET decision. ${ }^{42}$ Zhou et al reported that the $\operatorname{lncRNAH} H 9$ mediates breast cancer cell plasticity during EMT and MET plasticity by differentially sponging miR-200b/c and let-7b. ${ }^{43}$ However, whether $\operatorname{lncRNAH} H 19$ acts as an important inducer of EMT in papillary thyroid cancer remained unclear. Our analysis with ONCOMINE and cBioPortal databases, as well as TCGA datasets consistently demonstrated that $\operatorname{lncRNA} H 19$ was positively associated with key EMT factors. It was found that higher expression of $\operatorname{lncRNAH19}$ was correlated to elevated expression of Vimentin, as well as critical EMT-associated transcription factors, including ZEB2, Twist, and Snail2.

Loss or decreased E-cadherin and increased Vimentin are universally regarded as the hallmark of the EMT process. ${ }^{44}$ In the present study, we first used the human PTC cell line B-CPAP to characterize the potential role of $\ln C R N A H 19$ and found that $\operatorname{lncRNAH19}$ was able to regulate mRNA and protein expression of EMT markers E-Cadherin and Vimentin, which suggested that $l n c R N A H 19$ was pivotal driver of EMT in PTC cells. In addition, our study also showed that $\operatorname{lncRNA}$ $H 19$ promotes migration and invasion abilities of PTC cells. Shi et al reported that $\operatorname{lncRNAH19}$ predicts poor prognosis in patients with melanoma and regulates cell growth, invasion, migration, and EMT in melanoma cells. ${ }^{12}$ Liao et al reported that downregulation of $\ln c R N A H 19$ inhibits the migration and invasion of melanoma cells by inactivating the NF- $\kappa \mathrm{B}$ and PI3K/Akt signaling pathways. ${ }^{45}$

\section{Conclusion}

In summary, the expression level of $\ln c R N A H 19$ was significantly higher in PTC tissues than paired paracancerous tissue or normal tissues. Elevated lncRNA H19 expression was correlated with higher tumor burden of PTC. IncRNA $H 19$ regulates mRNA and protein expression of classic EMT markers E-Cadherin and Vimentin and promotes migration and invasion of PTC cells. IncRNA H19 is a critical oncogenic driver in PTC, and targeted therapy against $\operatorname{lncRNA}$ $H 19$ might be a potential avenue, in conjunction with other conventional therapy, to increase the efficacy for patients with PTC.

\section{Acknowledgments}

This work was partly supported by the Natural Science Foundation of Guangdong Province, China (No. 2018A030313562), National Natural Science Foundation of China (81600358), and Youth Innovative Talent Project of Colleges and Universities in Guangdong Province, China (No. 2017KQNCX073).

\section{Disclosure}

The authors report no conflicts of interest in this work.

\section{References}

1. Fagin JA, Wells SA. Biologic and clinical perspectives on thyroid cancer. N Engl J Med. 2016;375(11):1054-1067.

2. Teng H, Mao F, Liang J, et al. Transcriptomic signature associated with carcinogenesis and aggressiveness of papillary thyroid carcinoma. Theranostics. 2018;8(16):4345-4358.

3. Chen D, Qi W, Zhang P, et al. Investigation of BRAF V600E detection approaches in papillary thyroid carcinoma. Pathol Res Pract. 2018;214(2):303-307.

4. Kaiser MI. Encode and the parts of the human genome. Stud Hist Philos Biol Biomed Sci. 2018;72:28-37.

5. Davis CA, Hitz BC, Sloan CA, et al. The encyclopedia of DNA elements (encode): data portal update. Nucleic Acids Res. 2018;46(D1):D794-D801.

6. Thin KZ, Liu X, Feng X, Raveendran S, Tu JC. LncRNA-DANCR: a valuable cancer related long non-coding RNA for human cancers. Pathol Res Pract. 2018;214(6):801-805.

7. Achour C, Aguilo F. Long non-coding RNA and polycomb: an intricate partnership in cancer biology. Front Biosci. 2018;23:2106-2132.

8. Uszczynska-Ratajczak B, Lagarde J, Frankish A, Guigó R, Johnson R. Towards a complete map of the human long non-coding RNA transcriptome. Nat Rev Genet. 2018;19(9):535-548.

9. Yoshimura H, Matsuda Y, Yamamoto M, Kamiya S, Ishiwata T. Expression and role of long non-coding RNA H19 in carcinogenesis. Front Biosci. 2018;23:614-625.

10. Li H, Yu B, Li J, et al. Overexpression of lncRNA H19 enhances carcinogenesis and metastasis of gastric cancer. Oncotarget. 2014;5(8):2318-2329.

11. Guan G-F, Zhang D-J, Wen L-J, et al. Overexpression of lncRNA H19/ miR-675 promotes tumorigenesis in head and neck squamous cell carcinoma. Int J Med Sci. 2016;13(12):914-922.

12. Shi G, Li H, Gao F, Tan Q. IncRNA H19 predicts poor prognosis in patients with melanoma and regulates cell growth, invasion, migration and epithelial-mesenchymal transition in melanoma cells. Onco Targets Ther. 2018;11:3583-3595.

13. Zhao J, Ma S-T. Downregulation of IncRNA H19 inhibits migration and invasion of human osteosarcoma through the NF- $\mathrm{\kappa B}$ pathway. Mol Med Rep. 2018;17(5):7388-7394.

14. Mitchell B, Dhingra JK, Mahalingam M. BRAF and epithelial-mesenchymal transition: lessons from papillary thyroid carcinoma and primary cutaneous melanoma. Adv Anat Pathol. 2016;23(4):244-271.

15. Knauf JA, Sartor MA, Medvedovic M, et al. Progression of BRAFinduced thyroid cancer is associated with epithelial-mesenchymal transition requiring concomitant MAP kinase and TGF $\beta$ signaling. Oncogene. 2011;30(28):3153-3162.

16. Baquero P, Sánchez-Hernández I, Jiménez-Mora E, Orgaz JL, Jiménez B, Chiloeches A. (V600E)BRAF promotes invasiveness of thyroid cancer cells by decreasing E-cadherin expression through a Snail-dependent mechanism. Cancer Lett. 2013;335(1):232-241.

17. Kim TH, Kim YN, Kim HI, et al. Prognostic value of the eighth edition AJCC TNM classification for differentiated thyroid carcinoma. Oral Oncol. 2017;71:81-86.

18. Paulin C, Fabien N, Fusco A, et al. [Description of cell line established from human thyroid papillary cancer and secreting human chorionic gonadotropin hormone]. C R Acad Sci III. 1992;315(12):493-498. French 
19. Rhodes DR, Kalyana-Sundaram S, Mahavisno V, et al. Oncomine 3.0: genes, pathways, and networks in a collection of 18,000 cancer gene expression profiles. Neoplasia. 2007;9(2):166-180.

20. Gao J, Aksoy BA, Dogrusoz U, et al. Integrative analysis of complex cancer genomics and clinical profiles using the cBioPortal. Sci Signal. 2013;6(269):pl1.

21. Lin H-Y, Zeng D, Liang Y-K, Wei X-L, Chen C-F. GATA3 and TRPS1 are distinct biomarkers and prognostic factors in breast cancer: database mining for GATA family members in malignancies. Oncotarget. 2017;8(21):34750-34761.

22. Zeng D, Xiao Y, Zhu J, Peng C, Liang W, Lin H. Knockdown of nucleophosmin 1 suppresses proliferation of triple-negative breast cancer cells through activating CDH1/Skp2/p27kip1 pathway. Cancer Manag Res. 2019;11:143-156.

23. Shaukat AA. The rising trend in papillary thyroid carcinoma. True increase or over diagnosis? Saudi Med J. 2018;39(5):531.

24. Jillard CL, Scheri RP, Sosa JA. What is the optimal treatment of papillary thyroid cancer? Adv Surg. 2015;49:79-93.

25. Quagliariello V, Armenia E, Aurilio C, et al. New treatment of medullary and papillary human thyroid cancer: biological effects of hyaluronic acid hydrogel loaded with quercetin alone or in combination to an inhibitor of Aurora kinase. J Cell Physiol. 2016;231(8):1784-1795.

26. Huang Y, Qu S, Zhu G, et al. BRAF V600E Mutation-Assisted risk stratification of solitary Intrathyroidal papillary thyroid cancer for precision treatment. J Natl Cancer Inst. 2018;110(4):362-370.

27. Kwong N, Marqusee E, Gordon MS, et al. Long-term, treatment-free survival in select patients with distant metastatic papillary thyroid cancer. Endocr Connect. 2014;3(4):207-214.

28. Perez DS, Hoage TR, Pritchett JR, et al. Long, abundantly expressed non-coding transcripts are altered in cancer. Hum Mol Genet. 2008; 17(5):642-655.

29. Erho N, Buerki C, Triche TJ, Davicioni E, Vergara IA. Transcriptome-wide detection of differentially expressed coding and non-coding transcripts and their clinical significance in prostate cancer. J Oncol. 2012;2012(4):1-11.

30. Vu TN, Pramana S, Calza S, Suo C, Lee D, Pawitan Y. Comprehensive landscape of subtype-specific coding and non-coding RNA transcripts in breast cancer. Oncotarget. 2016;7(42):68851-68863.

31. Zhang T, Wang Y-R, Zeng F, Cao H-Y, Zhou H-D, Wang Y-J. LncRNA $\mathrm{H} 19$ is overexpressed in glioma tissue, is negatively associated with patient survival, and promotes tumor growth through its derivative miR-675. Eur Rev Med Pharmacol Sci. 2016;20(23):4891-4897.

32. Zhang L, Yang F, Yuan J-Hang, et al. Epigenetic activation of the miR200 family contributes to H19-mediated metastasis suppression in hepatocellular carcinoma. Carcinogenesis. 2013;34(3):577-586.
33. Lv J, Ma L, Chen X-L, Huang X-H, Wang Q. Downregulation of LncRNAH19 and miR-675 promotes migration and invasion of human hepatocellular carcinoma cells through AKT/GSK-3ß/Cdc25A signaling pathway. J Huazhong Univ Sci Technolog Med Sci. 2014;34(3): 363-369.

34. Yörüker EE, Keskin M, Kulle CB, Holdenrieder S, Gezer U. Diagnostic and prognostic value of circulating lncRNA H19 in gastric cancer. Biomed Rep. 2018;9(2):181-186.

35. Sun H, Wang G, Peng Y, et al. H19 lncRNA mediates 17ß-estradiolinduced cell proliferation in MCF-7 breast cancer cells. Oncol Rep. 2015;33(6):3045-3052.

36. Zhang Q, Li X, Li X, Li X, Chen Z. LncRNA H19 promotes epithelialmesenchymal transition (EMT) by targeting miR-484 in human lung cancer cells. J Cell Biochem. 2018;119(6):4447-4457.

37. Wang $\mathrm{P}$, Liu G, Xu W, Liu H, Bu Q, Sun D. Long noncoding RNA H19 inhibits cell viability, migration, and invasion via downregulation of IRS-1 in thyroid cancer cells. Technol Cancer Res Treat. 2017;16(6):1102-1112.

38. Lan X, Sun W, Dong W, et al. Downregulation of long noncoding RNA H19 contributes to the proliferation and migration of papillary thyroid carcinoma. Gene. 2018;646:98-105.

39. Liu N, Zhou Q, Qi Y-H, Wang H, Yang L, Fan Q-Y. Effects of long noncoding RNA H19 and microRNA let7a expression on thyroid cancer prognosis. Exp Mol Pathol. 2017;103(1):71-77.

40. Liu L, Yang J, Zhu X, Li D, Lv Z, Zhang X. Long noncoding RNA H19 competitively binds miR-17-5p to regulate YES1 expression in thyroid cancer. Febs J. 2016;283(12):2326-2339.

41. Jia L, Tian Y, Chen Y, Zhang G. The silencing of LncRNA-H19 decreases chemoresistance of human glioma cells to temozolomide by suppressing epithelial-mesenchymal transition via the $\mathrm{Wnt} / \beta$-catenin pathway. Onco Targets Ther. 2018;11:313-321.

42. Matouk IJ, Halle D, Raveh E, Gilon M, Sorin V, Hochberg A. The role of the oncofetal H19 lncRNA in tumor metastasis: orchestrating the EMT-MET decision. Oncotarget. 2016;7(4):3748-3765.

43. Zhou W, Ye X-L, Xu J, et al. The lncRNA H19 mediates breast cancer cell plasticity during EMT and Met plasticity by differentially sponging miR-200b/c and let-7b. Sci Signal. 2017;10(483):eaak955713.

44. Voon DC, Huang RY, Jackson RA, Thiery JP. The EMT spectrum and therapeutic opportunities. Mol Oncol. 2017;11(7):878-891.

45. Liao Z, Zhao J, Yang Y. Downregulation of lncRNA H19 inhibits the migration and invasion of melanoma cells by inactivating the NFKB and PI3K/Akt signaling pathways. Mol Med Rep. 2018;17(5):7313-7318. 


\section{Supplementary materials}

Table SI Primers used in RT-PCR

\begin{tabular}{|c|c|c|}
\hline Gene & Forward primer & Reverse primer \\
\hline $\mathrm{HI9}$ & 5'-TCTGAGAGATTCAAAGCCTCCAC-3' & 5'-GTCTCCACAACTCCAACCAGTG-3' \\
\hline E-cadherin & 5'-TGCCCAGAAAATGAAAAAGG-3' & 5'-GTGTATGTGGCAATGCGTTC-3' \\
\hline Vimentin & 5'-GAGAACTTTGCCGTTGAAGC-3' & 5'-TCCAGCAGCTTCCTGTAGGT-3' \\
\hline GAPDH & 5'-TGGACTCCACGACGTACTCAG-3' & 5'-ACATGTTCCAATATGATTCCA-3' \\
\hline
\end{tabular}

Abbreviation: RT-PCR, real-time PCR.

Table S2 Oligonucleotide sequences for siRNA constructs

\begin{tabular}{|l|l|}
\hline SiRNAs & sense $\left(5^{\prime}-3^{\prime}\right)$ \\
\hline siHI9-a & 5'-GCAGGACAUGACAUGGUCCTT-3' \\
siHI9-b & 5'-CCAACAUCA AAGACACCAU-3' \\
siNC & 5'-UUCUCCGAACGUGUCACGU-3' \\
\hline
\end{tabular}

Table S3 Antibodies used in this study

\begin{tabular}{|l|l|l|l|l|}
\hline Antibody & Catalog number & Company & Concentration rate & Species \\
\hline E-cadherin & $\mathrm{NCH}-38$ & Dako Denmark A/S (Glostrup, Denmark) & I:3000 & Rabbit \\
Vimentin & D2IH3 & Cell Signaling Technology (Danvers, MA, USA) & I:2000 & Rabbit \\
GAPDH & sc-32233 & Santa Cruz Biotechnology Inc. (Dallas, TX, USA) & I:3000 & Mouse \\
\hline
\end{tabular}




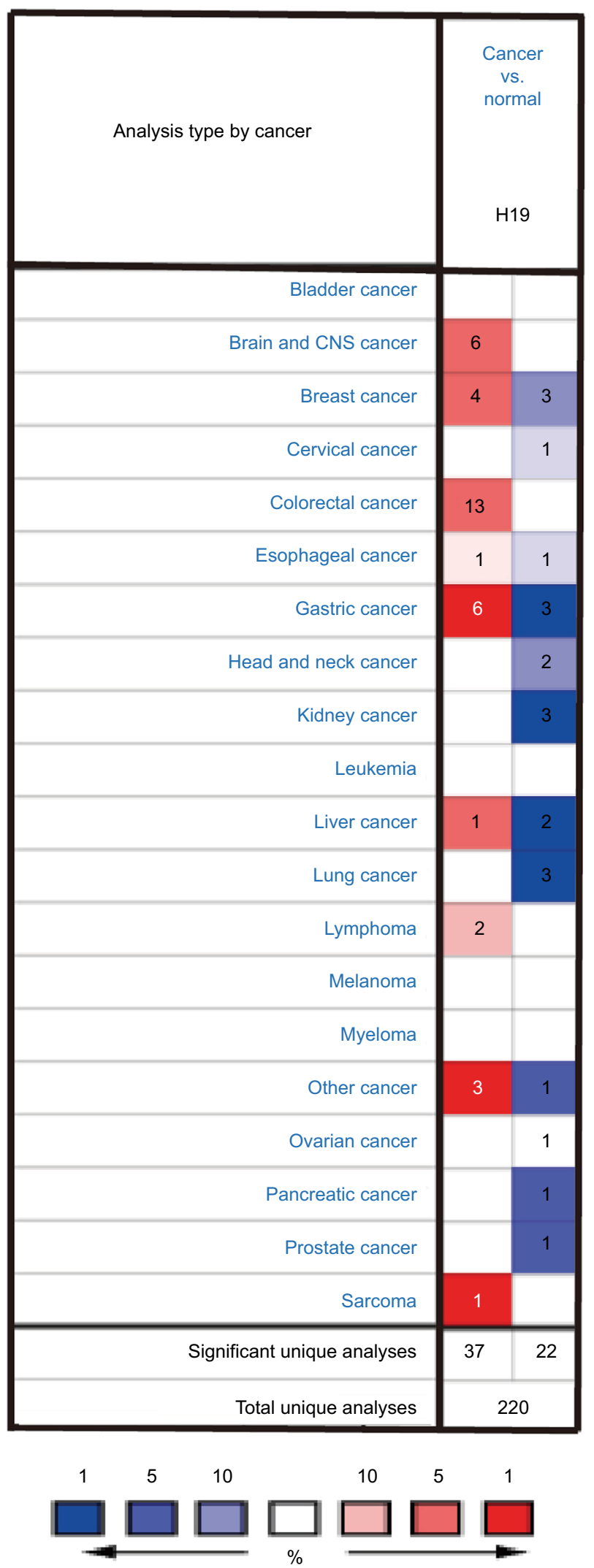

Figure SI Expression pattern of HI9 in different tumor types.

Notes: This figure shows the number of datasets with statistically significant RNA overexpression (red) or down-expression (blue) of the target gene (cancer vs. normal tissue). The $P$-value threshold is 0.01 . The number in each cell represents the number of analyses that meet the threshold within those analysis and cancer types. The gene rank was analyzed by percentile of target gene in the top of all genes measured in each research. Cell color is determined by the best gene rank percentile for the analyses within the cell. 


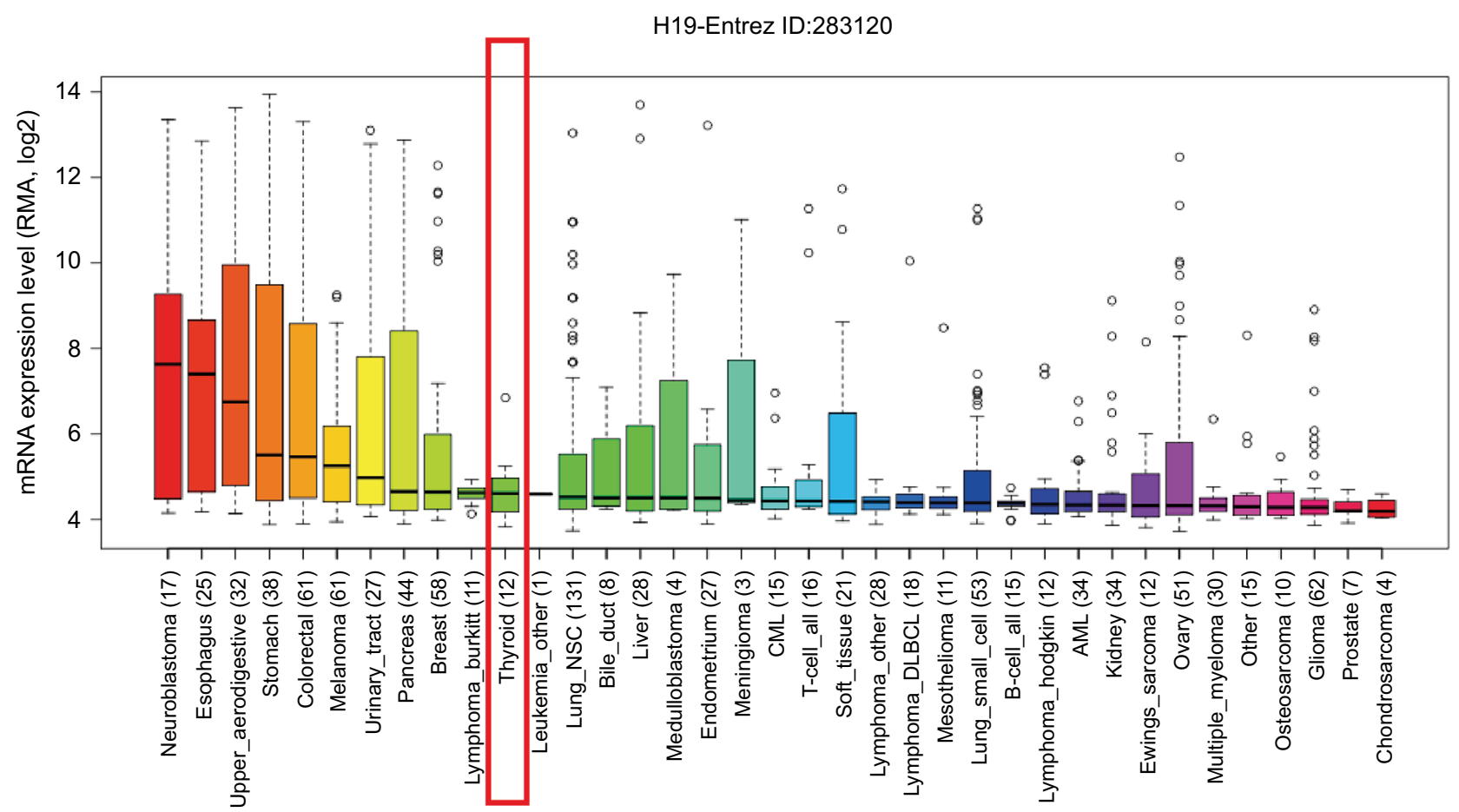

Figure S2 The RNA expression level of HI9 in thyroid cancer cells ranked eleventh highest in a variety of cancer cell lines from Cancer Cell Line Encyclopedia analysis (shown in red frame).

Abbreviations: RMA, return material authorization; CML, chronic myelocytic leukemia; AML, acute myelocytic leukemia; NSC, non-small cell.

Cancer Management and Research

\section{Publish your work in this journal}

Cancer Management and Research is an international, peer-reviewed open access journal focusing on cancer research and the optimal use of preventative and integrated treatment interventions to achieve improved outcomes, enhanced survival and quality of life for the cancer patient. The manuscript management system is completely online and includes

\section{Dovepress}

a very quick and fair peer-review system, which is all easy to use. Visit http://www.dovepress.com/testimonials.php to read real quotes from published authors. 